\title{
ANALISIS MULTIKRITERIA DALAM PEMILIHAN SISTEM PEMROSESAN SAMPAH DI KABUPATEN KLUNGKUNG, PROVINSI BALI \\ (Multicriteria Analysis for Selecting Waste Processing System in Klungkung Regency, Bali Province)
}

\author{
Mochammad Chaerul*, Elprida Agustina, dan I Made Wahyu Widyarsana \\ Program Studi Rekayasa Infrastruktur Lingkungan, Departemen Teknik Lingkungan, \\ Fakultas Teknik Sipil dan Lingkungan, Institut Teknologi Bandung, \\ Jalan Ganesha No. 10 Bandung 40132.
}

*Penulis korespondensi. Tel: 022 2534187. Email: m.chaerul@ftsl.itb.ac.id.

Diterima: 24 April 2019

Disetujui: 20 Mei 2019

\begin{abstract}
Abstrak
Berbagai macam upaya dilakukan oleh pemerintah untuk menciptakan lingkungan suatu kota yang bersih, di antaranya melalui penyediaan fasilitas sistem pemrosesan sampah sebagai tahapan akhir dalam pengelolaan sampah. Saat ini, Kabupaten Klungkung, Provinsi Bali memiliki 3 alternatif sistem pemrosesan sampah yang dapat diaplikasikan, yaitu: menggunakan tempat pemrosesan akhir sampah (TPA) eksisting Regional Bangli, membangun TPA baru tersendiri untuk Klungkung, dan pemrosesan akhir di Tempat Olah Sampah Setempat (TOSS). Penelitian ini bertujuan untuk memilih sistem pemrosesan sampah yang paling optimal dengan mempertimbangkan 4 kriteria, yaitu lingkungan, ekonomi, sosial dan teknis (analisis multikriteria) dengan menggunakan pendekatan Analytical Hierarchy Process (AHP). Setiap kriteria memiliki beberapa sub kriteria yang dimintakan kepada 35 orang responden yang mewakili 5 institusi pemerintahan daerah terkait untuk dilakukan penilaian perbandingan berpasangan. Penilaian juga dilakukan untuk mengevaluasi setiap alternatif terhadap semua sub kriteria dan kriteria. Secara global, responden lebih memilih pencegahan pencemaran lingkungan (nilai bobot 0,16 ) sebagai sub kriteria terpenting dari total 13 sub kriteria yang tersedia. Urutan kriteria yang dianggap lebih penting adalah lingkungan (nilai bobot 0,543$)$, sosial $(0,181$ ), ekonomi $(0,146)$ dan teknis $(0,130)$. Untuk alternatif pengolahan sampah di fasilitas TOSS dianggap yang paling optimal (total nilai 0,47) disusul TPA Regional Bangli $(0,28)$, terakhir TPA baru $(0,25)$. Suatu alternatif sistem pemrosesan sampah dengan kelebihan dan kekurangan masing-masing harus dipilih yang paling dapat diterima oleh berbagai stakeholder terkait sehingga diharapkan dapat menjadi bagian dari suatu sistem pengelolaan sampah yang berkelanjutan dari suatu kota.
\end{abstract}

Kata kunci: analisis multikriteria, sampah domestik, analytical hierarchy process, sistem pemrosesan sampah.

\begin{abstract}
In order to create a city clean, efforts are taken by government including provision of waste processing system facility as part of waste management system. Recently, Klungkung Regency, Bali Province has 3 alternatives of waste processing system to be applied, namely: utilizing the existing regional final disposal site (TPA) of Bangli, building a new TPA facility dedicated for Klungkung area only, and on-site waste processing facility (TOSS). The study aims to determine the most optimal of waste processing system by considering 4 criteria, namely environment, economic, social and technical (multicriteria analysis) with the help of Analytical Hierarchy Process (AHP). Each criterion having several sub criterions were assessed by 35 respondents representing 5 local government's institutions by applying pair wise comparison. The asessement were also performed to evaluate the alternatives to the given criteria and sub criterion. In global, respondents preferred to put environmental pollution prevention (weight of 0.16) as the most important among total $13 \mathrm{sub}$ criterions available. Among the criteria, environment (weight of 0.543) was more prioritized than social (0.181), economic (0.146) and technical (0.130) aspects. Other result showed that TOSS (total value of 0.47) was more preferred than existing TPA of Bangli (0.28), and new TPA of Klungkung (0.25). An alternative of waste processing with its advantages and disadvantages should be chosen and acceptable by the related stakeholders, thus the facility becomes part of sustainable waste management system in a city.
\end{abstract}

Keywords: multicriteria analysis, domestric waste, analytical hierarcy process, waste processing system.

\section{PENDAHULUAN}

Di sebagian besar kota besar di Indonesia, peningkatan populasi telah menciptakan kondisi lingkungan hidup yang buruk yang secara signifikan dan mempengaruhi kondisi sanitasi. Sampah atau buangan sebagai konsekuensi dari aktivitas manusia menjadi tantangan bagi kota-kota di Indonesia, terutama untuk untuk kawasan pariwisata seperti di Kabupaten Klungkung, Bali. 
Sistem pengelolaan di kawasan pariwisata harus lebih baik dibandingkan di kawasan lainnya (Davenport dan Davenport, 2006) karena akan mempengaruhi kenyamanan para wisatawan dan pendapatan daerah (Chen dkk, 2005).

Kabupaten Klungkung terdiri dari 4 kecamatan yang terdiri dari 3 kecamatan di daratan Pulau Bali dan 1 kecamatan di wilayah kepulauan Nusa Penida. Pada tahun 2016 populasi penduduk di Kabupaten Klungkung mencapai 131.230 jiwa dan menerima 378.894 wisatawan dengan 31 lokasi wisata yang semakin meningkat jumlahnya dari tahun-tahun sebelumnya (Badan Pusat Statistik Kabupaten Klungkung, 2017). Peningkatan aktivitas di Kabupaten ini mengakibatkan peningkatan jumlah timbulan sampah yaitu sebesar $228 \mathrm{~m}^{3} /$ hari di tahun 2011 (Satuan Kerja PSPLP Provinsi Bali, 2011) dan menjadi $658 \mathrm{~m}^{3} /$ hari di tahun 2017 (Satuan Kerja PSPLP Provinsi Bali, 2017).

Kabupaten Klungkung sebenarnya sempat memiliki lokasi tempat pemrosesan akhir sampah (TPA) Sente yang menerima semua sampah yang dihasilkan. Adanya permasalahan sosial dan lingkungan membuat TPA Sente tersebut sempat ditutup pada akhir tahun 2017, akan tetapi saat ini sudah dioperasikan kembali karena keterbatasan lahan TPA yang dimiliki Kabupaten Klungkung. Lebih jauh lagi, saat ini Pemerintah berencana membangun TPA baru yang hanya akan menerima sampah dari Kabupaten Klungkung. TPA Regional Sarbagita juga dipergunakan untuk menimbun sampah yang dihasilkan dari Kabupaten Klungkung, walaupun sebenarnya TPA Regional Bangli lebih layak untuk dipergunakan karena lokasinya yang lebih dekat. Hanya saja saat ini masih diperlukan surat kesepakatan dengan Pemerintah Provinsi Bali agar Kabupaten Klungkung dapat membuang sampahnya di TPA Regional Bangli. Selain mengandalkan keberadaan TPA, Kabupaten Klungkung juga berinovasi untuk memproses sampah menjadi pellet sebagai bagian dari implementasi konsep Waste to Energy di fasilitas Tempat Olah Sampah Setempat (TOSS) yang tersebar di hampir setiap kelurahan di Kabupaten Klungkung.

Terdapat berbagai macam kriteria yang perlu diperhatikan agar sistem pengelolaan sampah suatu kota dapat diterima oleh berbagai macam stakeholder terkait. Untuk keperluan ini dapat dipertimbangkan teknik analisis multikriteria (multicriteria analysis) menggunakan metode Analytical Hierarchy Process (AHP). Metoda analisis ini telah berhasil dikembangkan antara lain oleh Gunamantha dkk (2010), Ekmekcioglu dkk (2010), De Feo dan De Gisi (2014), Vucijak dkk (2015), Yap dan Nixon (2015), Chamdra dkk
(2015), serta Milutinovic dkk (2016). Pada penelitian ini dilakukan kajian analisis prinsip analisis multikriteria (multicriteria analysis) menggunakan metode Analytical Hierarchy Process (AHP) yang ditujukan untuk memilih alternatif sistem pemrosesan sampah di Kabupaten Klungkung dengan mempertimbangkan penilaian dari stakeholder terkait. Sistem pemrosesan sampah merupakan bagian dari sistem pengelolaan sampah suatu kota sehingga dengan terpilihnya suatu sistem pemrosesan sampah yang terbaik diharapkan dapat menciptakan sistem pengelolaan sampah yang lebih berkelanjutan.

\section{METODE PENELITIAN}

Terdapat berbagai macam metode multikriteria analisis yang dapat digunakan dalam pengelolaan sampah, diantaranya dengan menggunakan metode Analytical Hierarchy Process (AHP). AHP merupakan proses berpikir yang komprehensif, logis, terstruktur, dan sesuai untuk digunakan dalam upaya penyelesaian masalah yang menyangkut berbagai macam kriteria yang melibatkan penilaian dari berbagai stakeholder yang terkait (Saaty, 2004). Sesuai standar metode AHP, kuesioner dibuat berdasarkan susunan hierarki, sesuai dengan urutan goal (tujuan), kriteria, subkriteria, dan alternatif (Gambar 1). Kriteria dan subkriteria disusun berdasarkan tingkatannya dan digunakan untuk membentuk matriks pembandingan berpasangan (pairwise comparison matrix). Matriks ini digunakan untuk membandingkan beberapa kriteria dan alternatif yang setingkat dan menentukan nilai prioritas masing-masing kriteria dan alternatif.

Goal atau tujuan yang ingin dicapai adalah untuk memilih sistem pemrosesan sampah yang dapat diaplikasikan di Kabupaten Klungkung. Kriteria dalam penelitian ini ditentukan berdasarkan studi literatur dari jurnal internasional maupun penelitian sebelumnya. Penelitian ini terdiri dari 4 (empat) kriteria yaitu kriteria lingkungan, ekonomi, sosial, dan teknis. Keempat kriteria tersebut didapatkan dari hasil diskusi dengan berbagai macam stakeholder sebelum dilakukan wawancara dan berdasarkan penelusuran berbagai literatur, Sebenarnya kriteria ekonomi bisa dikuantifikasi secara pasti, akan tetapi penilaian kepada responden tetap diminta untuk mengantisipasi kemungkinan penggunaan berbagai macam prasarana sarana (antara lain: truk sampah, jembatan timbang, pengolah lindi, mesin pencacah, dan lain-lain) dan kapasitas pemrosesan yang dapat diaplikasikan. Kesemua variasi tersebut bisa berimplikasi pada penilaian dari responden terhadap sistem pemrosesan sampah. Masing-masing kriteria 
tersebut didetailkan menjadi beberapa sub kriteria yang dapat dilihat pada Tabel 1 .

Dalam penelitian ini, alternatif yang akan dipilih didasarkan atas alternatif pemrosesan sampah yang dimiliki oleh Pemerintah Kabupaten Klungkung, yaitu:

- Alt \#1: Pemrosesan sampah yang dihasilkan dari Kabupaten Bangli dilakukan di TPA Regional Bangli, yang saat ini memang sudah digunakan oleh beberapa Kabupaten, yaitu: Bangli, Klungkung, Gianyar, dan Karangasem.

- Alt \#2: Pemrosesan sampah yang dihasilkan dari Kabupaten Bangli dilakukan di lokasi TPA yang baru yang rencananya hanya menerima sampah dari Kabupaten Bangli saja.

- Alt \#3: Pemrosesan sampah yang dihasilkan dari Kabupaten Bangli dilakukan di fasilitas TOSS yang rencananya akan dibangun di setiap Kelurahan.

Form kuesioner pemilihan sistem pemrosesan sampah di Kabupaten Klungkung telah disiapkan untuk mempermudah wawancara yang dilakukan terhadap responden yang dipilih. Responden yang dipilih mewakili berbagai instansi pemerintahan daerah yang berkaitan dengan pengelolaan sampah secara umum. Responden hanya ditujukan kepada pemerintah daerah dikarenakan permasalahan dan juga alternatif yang sudah definitif dan sangat bergantung kepada keputusan pengambil kebijakan di Kabupaten Klungkung. Pendapat dari setiap responden dianggap setimbang; tidak ada pendapat dari satu responden yang dianggap lebih penting daripada pendapat responden lainnya. Terdapat total 35 responden dengan masing-masing 7 responden yang mewakili: Dinas Lingkungan Hidup dan Pertanahan (DLHP) Kabupaten Klungkung, Sekertaris Daerah Kabupaten Klungkung, BAPPEDA Kabupaten Klungkung, Satuan Kerja Pengembangan Sistem Penyehatan Lingkungan Permukiman Provinsi Bali, dan UPT Pengelolaan Sampah Provinsi Bali.

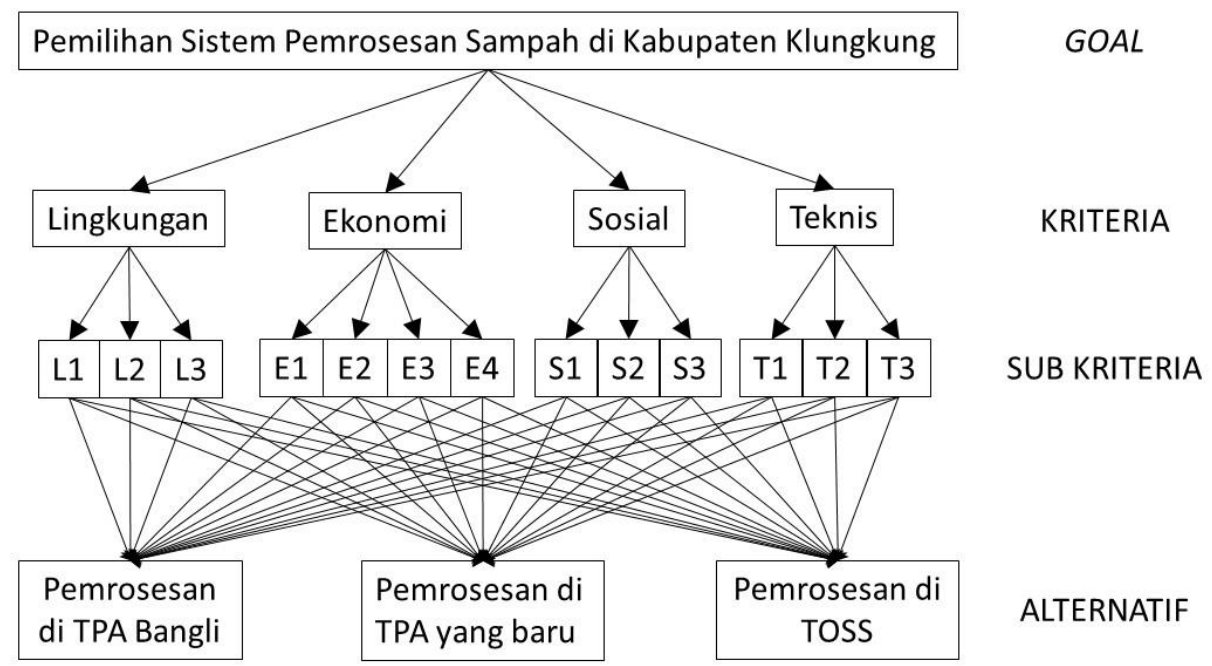

Gambar 1. Hirarki penelitian.

Tabel 1. Kriteria dan sub kriteria yang digunakan dalam AHP.

\begin{tabular}{cccl}
\hline No & Kriteria (Kode) & Kode Sub Kriteria & \multicolumn{1}{c}{ Sub-Kriteria } \\
\hline 1. & Lingkungan (L) & L1 & Mencegah pencemaran lingkungan (air, tanah \& udara) \\
& & L2 & Estetika \\
2. & Ekonomi (E) & L3 & Vektor penyakit \\
& & E1 & Biaya investasi \\
& & E2 & Biaya operasional \\
3. & E3 & Pendapatan dari hasil olahan sampah \\
& & E4 & Biaya pemeliharaan \\
& & S1 & Penerimaan masyarakat \\
4. & Teknis $(\mathrm{T})$ & S2 & Penyerapan tenaga kerja dan lapangan usaha \\
& & T1 & Kesiapan tenaga kerja \\
& & T2 & Kemudahan pengoperasian \\
& & T3 & Kesesuaian dengan timbulan dan karakteristik sampah \\
\hline
\end{tabular}

Tabel 2. Indeks random konsistensi.

\begin{tabular}{cccccccccccc}
\hline $\mathrm{n}$ & $1-2$ & 3 & 4 & 5 & 6 & 7 & 8 & 9 & 10 & 11 & 12 \\
\hline $\mathrm{RI}$ & 0,00 & 0,58 & 0,90 & 1,12 & 1,24 & 1,32 & 1,41 & 1,49 & 1,51 & 1,54 & 1,56 \\
\hline
\end{tabular}


Tabel 3. Penilaian kriteria.

\begin{tabular}{lccccc}
\hline Kriteria & $\mathrm{L}$ & $\mathrm{E}$ & $\mathrm{S}$ & $\mathrm{T}$ & $\mathrm{PV}$ \\
\hline $\mathrm{L}$ & 1,000 & 4,851 & 3,234 & 2,986 & 0,543 \\
$\mathrm{E}$ & 0,206 & 1,000 & 0,907 & 1,299 & 0,146 \\
$\mathrm{~S}$ & 0,309 & 1,103 & 1,000 & 1,673 & 0,181 \\
$\mathrm{~T}$ & 0,335 & 0,770 & 0,598 & 1,000 & 0,130 \\
\hline
\end{tabular}

Setiap responden dimintakan pendapat untuk melakukan pembobotan antar kriteria dan subkriteria terhadap masing-masing alternatif sistem pemrosesan sampah di Kabupaten Klungkung dengan sistem 7-skala, yaitu 1: Bila satu elemen sama-sama penting, 3: Bila satu elemen sedikit lebih penting dibanding elemen lain, 5: Bila satu elemen lebih penting dibanding elemen lain, 7: Bila satu elemen sangat lebih penting dibanding elemen lain.

Angka 2, 4, 6 diberikan bila kepentingan satu elemen dibanding elemen lain berada diantara range tersebut. Nilai Satu per angka diatas diberikan bila satu elemen lebih tidak penting dibanding elemen lain.

Untuk melihat konsistensi penilaian dari responden maka analisis rasio konsistensi (consistency ratio). Nilai rasio konsistensi diharapkan kurang dari atau sama dengan 10\% agar suatu data bisa dikatakan konsisten. Perhitungan rasio konsistensi dapat dilakukan dengan menggunakan formula (1) dan (2).

$\mathrm{C}_{\mathrm{I}}=\left(\lambda_{\text {maks }}-\mathrm{n}\right) /(\mathrm{n}-1)$

$\mathrm{C}_{\mathrm{R}}=\mathrm{C}_{\mathrm{I}} / \mathrm{R}_{\mathrm{I}}$

dimana:

$\mathrm{C}_{\mathrm{I}}=$ indeks konsistensi

$\lambda_{\text {maks }}=$ hasil perhitungan matrik dibagi elemen

$\mathrm{n}=$ elemen

$\mathrm{C}_{\mathrm{R}}=$ rasio konsistensi

$\mathrm{R}_{\mathrm{I}}$ = indeks random konsistensi, yang dipengaruhi oleh jumlah elemen (Tabel 2).

Penilaian antar subkriteria untuk masingmasing kriteria dilakukan untuk mengetahui subkriteria yang dianggap lebih penting oleh responden di setiap kriteria. Penilaian ini disebut sebagai perbandingan lokal. Perbandingan secara global juga dilakukan untuk melihat perbandingan semua subkriteria dari semua kriteria. Perhitungan bobot global didapat dengan menjumlahkan vektor prioritas dari seluruh subkriteria dan kemudian melakukan pembagian masing-masing subkriteria dengan jumlah total kriteria yaitu 4 (empat) buah kriteria.

\section{HASIL DAN PEMBAHASAN}

\section{Penilaian Kriteria}

Perbandingan kriteria dilakukan dalam sebuah matriks perbandingan sehingga nilai sintesa yang merupakan urutan prioritas dari kriteria tersebut. Kriteria yang disusun terdiri dari lingkungan, ekonomi, sosial, dan teknis. Hasil perhitungan tersebut seperti yang dapat dilihat pada Tabel 3 .

Dari penilaian kriteria didapat bahwa lingkungan menjadi kriteria dengan prioritas tertinggi dengan nilai bobot yang relatif jauh lebih besar (nilai bobot 0,543) dibandingkan dengan 3 kriteria yang lain. Kriteria berikutnya yang dianggap lebih penting untuk dipertimbangkan dalam pemilihan sistem pemrosesan sampah di Kabupaten Klungkung adalah sosial $(0,181)$, diikuti kriteria ekonomi $(0,146)$, dan kriteria yang dianggap paling tidak penting adalah teknis $(0,130)$. Nilai consistency ratio (CR) untuk penilaian kriteria adalah $2,4 \%$ yang menunjukkan bahwa hasil penghitungan ini cukup konsisten dan berada dalam batas penerimaan (lebih kecil atau sama dengan $10 \%$ ).

Faktor lingkungan dalam penelitian ini didefinisikan sebagai faktor yang berhubungan dengan dampak lingkungan seperti pencemaran, estetika, dan juga kesehatan lingkungan. Kriteria ini diharapkan dapat dipenuhi dengan pemrosesan sampah yang baik atau dapat disebut teknologi ramah lingkungan.

\section{Penilaian Sub kriteria}

Hasil perbandingan bobot global dan lokal untuk semua subkriteria yang terdapat di 4 kriteria dapat dilihat pada Gambar 2. Dari perbandingan global semua subkriteria terlihat bahwa subkriteria pencegahan pencemaran (L1, dengan bobot 0,16 ) dan subkriteria kesesuaian sistem pemrosesan sampah dengan timbulan dan karakteristik sampah (T2, dengan bobot 0,11 ) dinilai menjadi preferensi responden yang lebih penting dibandingkan dengan 11 subkriteria lainnya. Sedangkan subkriteria yang memiliki nilai preferensi terkecil dari responden adalah estetika (L2, dengan bobot 0,03 ) dan pendapatan dari hasil olahan sampah (E3, dengan bobot 0,05$)$. Hasil perbandingan global tersebut menunjukkan bahwa responden di Kabupaten Klungkung memiliki kesadaran lingkungan dan menginginkan efektifitas pemrosesan sampah yang lebih baik ketika akan mengaplikasikan suatu sistem tertentu dengan tidak lebih memprioritaskan aspek estetika dan profit yang bisa didapat.

Dari perbandingan lokal didapatkan hasil subkriteria mana dalam 1 kriteria yang lebih diprioritaskan oleh responden dalam memilih sistem pemrosesan sampah di Kabupaten Klungkung. Preferensi prioritas tertinggi dari ketiga subkriteria di kriteria lingkungan adalah mencegah pencemaran air, udara, dan tanah (L1) sebesar 0,62 diikuti pengendalian vektor penyakit (L3) sebesar 0,25 , dan yang terakhir adalah mengenai estetika 


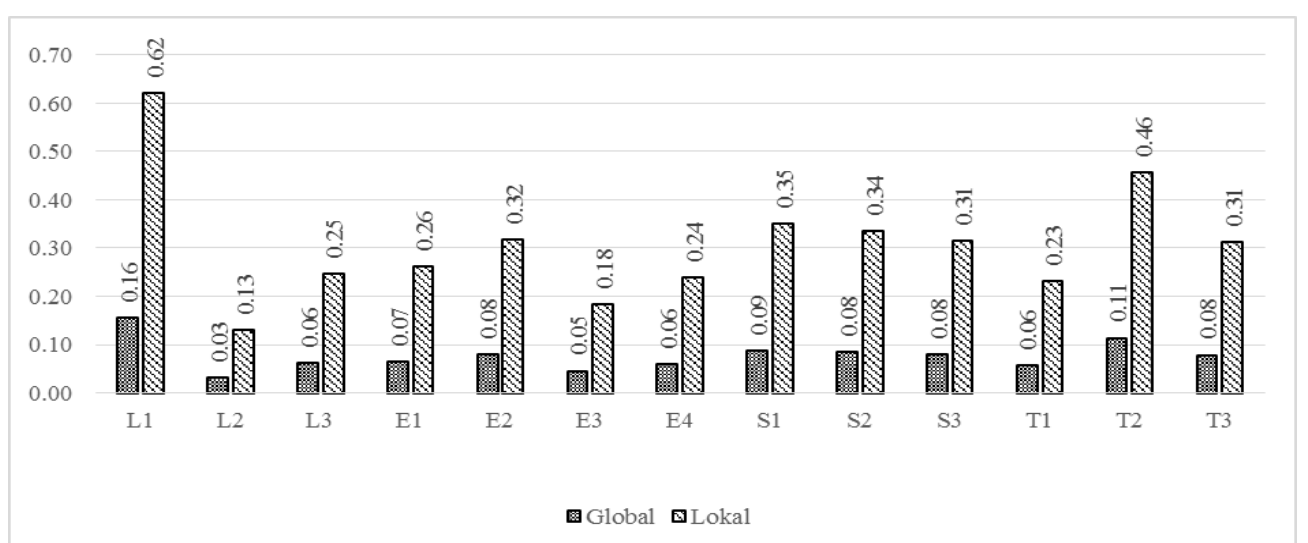

Gambar 2. Penilaian bobot prioritas subkriteria secara global dan lokal.

(L2) sebesar 0,13. Berdasarkan hasil tersebut terlihat bahwa sistem pemrosesan sampah yang lebih dikehendaki untuk dapat diaplikasikan di Kabupaten Klungkung adalah yang lebih dapat mencegah pencemaran lingkungan dan pengendalian vektor penyakit daripada sekadar aspek estetikanya.

Walaupun dengan nilai bobot tidak terlalu beda jauh, reponden menempatkan subkriteria biaya operasional (E2) memiliki preferensi yang lebih tinggi dibandingkan subkriteria lainnya yang dinilai di kriteria ekonomi. Subkriteria berikutnya yang dinilai relatif lebih rendah oleh responden adalah biaya investasi (E1), biaya pemeliharaan (E4), dan pendapatan dari hasil olahan sampah (E3). Berdasarkan nilai bobot dari semua subkriteria di kriteria ekonomi terlihat bahwa dalam mengaplikasikan pemrosesan sampah di Kabupaten Klungkung, responden lebih memprioritaskan sistem yang membutuhkan biaya operasional, investasi dan pemeliharaan yang lebih rendah dibandingkan pemrosesan sampah yang sekadar menghasilkan produk samping yang dapat dimanfaatkan kembali.

Urutan preferensi prioritas responden dari ketiga subkriteria yang dinilai dari kriteria sosial adalah: penerimaan masyarakat (S1, sebesar 0,35), penyerapan tenaga kerja dan lapangan usaha (S2, sebesar 0,34), dan yang terakhir kesiapan tenaga kerja (S3, sebesar 0,31). Nilai di antara ketiga subkriteria memiliki selisih yang relatif kecil, artinya semua subkriteria sosial memiliki tingkat preferensi yang tidak berbeda jauh. Walaupun demikian, prioritas responden terhadap pemrosesan sampah di Kabupaten Klungkung lebih menghendaki suatu sistem yang dapat diterima oleh masyarakat.

Diantara 3 subkriteria yang dinilai dari kriteria teknis didapatkan bahwa responden dalam memilih pemrosesan sampah di Kabupaten Klungkung lebih memprioritaskan sistem yang sesuai dengan timbulan dan karakteristik sampah (T2) daripada
Tabel 4. Penilaian alternatif terhadap subkriteria.

\begin{tabular}{lllll}
\hline \multicolumn{1}{c}{ Kriteria } & & ALT.1 & ALT.2 & ALT.3 \\
\hline \multirow{4}{*}{ Lingkungan } & L1 & 0,04 & 0,05 & 0,07 \\
& L2 & 0,01 & 0,01 & 0,02 \\
& L3 & 0,02 & 0,01 & 0,03 \\
& E1 & 0,02 & 0,01 & 0,03 \\
\multirow{4}{*}{ Sosial } & E2 & 0,03 & 0,02 & 0,03 \\
& E3 & 0,01 & 0,01 & 0,02 \\
\multirow{4}{*}{ Teknis } & E4 & 0,02 & 0,01 & 0,03 \\
& S1 & 0,02 & 0,02 & 0,05 \\
& S2 & 0,01 & 0,02 & 0,05 \\
& S3 & 0,02 & 0,02 & 0,04 \\
Jumlah & T1 & 0,02 & 0,01 & 0,02 \\
TOTAL & T2 & 0,03 & 0,03 & 0,05 \\
& T3 & 0,03 & 0,02 & 0,03 \\
\hline
\end{tabular}

kemudahan pengoperasian (T3) dan pemeliharaan teknologi (T1).

\section{Penilaian Alternatif}

Dari 3 alternatif yang tersedia dan dimintakan penilaiannya kepada responden, Alternatif 3 yaitu pemrosesan sampah dengan fasilitas TOSS di setiap desa (nilai 0,47) lebih diprioritaskan daripada alternatif pemrosesan sampah di TPA Regional Bangli (Alternatif 1, nilai 0,28) dan pemrosesan sampah di TPA yang baru (Alternatif 2, nilai 0,25). Apabila dilihat lebih detail, Alternatif 3 dinilai memiliki kelebihan di semua subkriteria dibandingkan Alternatif lainnya. Sebaliknya, Alternatif 2 dinilai memiliki kelemahan di semua subkriteria yang dinilai. Sedangkan Alternatif 1 dianggap sebagai yang paling moderat dibandingkan kedua alternatif. Dengan hasil penilaian alternatif ini menunjukkan bahwa menilai bahwa Alternatif 3 dapat memenuhi semua subkriteria yang diinginkan responden di Kabupaten Klungkung. Penilaian detail dari setiap alternatif terhadap semua subkriteria dapat dilihat pada Tabel 4. 


\section{KESIMPULAN}

Secara umum, pemecahan permasalahan sampah di suatu kota melibatkan beberapa kriteria untuk dianalisis (multicriteria analysis). Penelitian ini menjadikan berbagai pihak pengambil keputusan di pemerintahan daerah sebagai responden untuk memilih sistem pemrosesan sampah yang paling sesuai untuk diaplikasikan di Kabupaten Klungkung dengan menggunakan metode Analytic Hierarchy Process (AHP) sebagai metode analisis multikriteria.

Dari 4 kriteria yang telah ditentukan, kriteria lingkungan lebih diprioritaskan oleh responden dibandingkan kriteria sosial, ekonomi dan teknis. Masing-masing kriteria memiliki beberapa subkriteria yang dinilai secara lokal dalam 1 kriteria dan secara global terhadap keseluruhan kriteria. Dari total 13 subkriteria yang dinilai, subkriteria pencegahan pencemaran di kriteria lingkungan (L1) dan subkriteria kesesuaian sistem pemrosesan sampah dengan timbulan dan karakteristik sampah di kriteria teknis (T2) dinilai lebih penting dibandingkan subkriteria lainnya.

Dari 3 alternatif yang dinilai, alternatif pemrosesan sampah di fasilitas TOS di setiap desa (Alternatif 3) dinilai paling mendekati pemenuhan terhadap semua kriteria dan subkriteria yang ada dibandingkan alternatif pemrosesan sampah di TPA Regional Bangli (Alternatif 1) dan pemrosesan sampah di TPA yang baru di Klungkung.

\section{DAFTAR PUSTAKA}

Chamdra, S., Pellokila, M.R., dan Ramang, R., 2015. Analisis Teknologi Pengolahan Sampah di Kupang dengan Proses Hirarki Analitik dan Metode Valuasi Kontingensi. J. Manusia \& Lingkungan, 22(3):350-356.

Chen, M.C., Ruijs, A., and Wesseler, J., 2005. Solid Waste Management on Small Island: The Case of Green Island, Taiwan. Resources, Concervation, and Recycling, 45:31-47.

Davenport, J., and Davenport, J.L., 2006. The Impact of Tourism dan Personal Leisure Transport on Coastal Environments: A
Review. Estuarine, Coastal, and Shelf Science, 67:280-292.

De Feo, G., and De Gisi, S., 2014. Using MCDA and GIS for Hazardous Waste Landfill Sitting considering Land Scarcity for Waste Disposal. Waste Management, 34(11):2225-2238.

Ekmekcioglu, M., Kaya, T., and Kahraman, C., 2010. Fuzzy Multicriteria Disposal Method and Site Selection for Municipal Solid Waste. Waste Management, 30(9):1729-1736.

Gunamantha, M., Fandeli, C., Shalihuddin, D.T., dan Sarto, S., 2010. Life Cycle Assessment Pilihan Pengelolaan Sampah: Studi Kasus Wilayah Kartamantul Provinsi D.I. Yogyakarta. J. Manusia \& Lingkungan, 17(2):78-88.

Badan Pusat Statistik Kabupaten Klungkung, 2017. Kabupaten Klungkung Dalam Angka 2016.

Milutinovic, B., Stefanovic, G., Dekic, P.S., Milailovic, I., and Tomic, M., 2016. Environmental Assessment of Waste Management Scenarios with Energy Recovery Using Life Cycle Assessment and MultiCriteria Analysis. Energy, 137:917-926.

Saaty T.L., 2004. Decision Making-The Analytic Hierarchy and Network Processes (AHP/ANP). Journal of Systems Science and Systems Engineering, 13(1):1-35.

Satuan Kerja PSPLP Provinsi Bali, 2011. PTMP Kabupaten Klungkung, Bali. Pemerintah Kabupaten Klungkung.

Satuan Kerja PSPLP Provinsi Bali, 2017. PTMP Kabupaten Klungkung, Bali. Pemerintah Kabupaten Klungkung.

Vucijak, B., Kurtagic, S.M., and Silajdzic, I., 2015. Multicriteria Decision Making in Selecting Best Solid Waste Management Scenario: A Municipal Case Study from Bosnia and Herzegovina. Journal of Cleaner Production, 130:166-174.

Yap, H.Y., and Nixon, J.D., 2015. A Multi Criteria Analysis of Options for Energy Recovery From Municipal Solid Waste in India and the UK. Waste Management, 46:265-277. 